\title{
Paget's Disease in a 5-year-old: Acute Response to Human Calcitonin
}

\author{
N. J. Y. WOODHOUSE, M. T. FISHER, G. SIGURDSSON， G. F. JOPLIN， I. MACINTYRE
}

British Medical fournal, 1972, 4, 267-269

\section{Summary}

A five-year-old boy presented with a three-and-a-halfyear history of repeated bone fractures and progressive bone deformity. The excretion of hydroxyproline in the urine was greatly increased, and serum alkaline phosphatase and acid phosphatase levels were very high. These abnormalities together with the findings on bone histology and radiology suggested a diagnosis of juvenile Paget's disease. Human calcitonin reduced the bone turnover as evidenced by an immediate and sustained fall in urine hydroxyproline excretion, while calcium and phosphate balance became more positive. This treatment is therefore being continued on an outpatient basis.

\section{Introduction}

The term "juvenile Paget's disease" was first used to describe an unusual bone disease occurring in an 11-year-old boy (Choremis et al., 1958). Several further examples of what appears to be the same or a similar disorder have been reported and variously named "fragile bones and macrocranium" (Bakwin and Elder, 1956), "hyperostosis corticalis deformans juvenilis" (Swoboda, 1958), "chronic idiopathic hyperphosphatasia" (Caffey, 1961), "chronic progressive osteopathy with hyperphosphatasia" (Marshall and Moncrieff, 1962), "osteochalasia desmalis familiaris" (Facon et al., 1964), "familial osteoectasia" (Stimmerman, 1966), "hereditary hyperphosphatasia (Thompson et al., 1969), and "congenital hyperphosphatasia" (Eyring and Eisenberg, 1968).

The disease is apparently transmitted as an autosomal recessive trait (Thompson et al., 1969) and characterized by deformity in early life, fragile bones, and raised serum alkaline phosphatase and acid phosphatase levels. Urine hydroxyproline excretion is increased, and studies using tetracycline labelling of bone and stable strontium measurements have confirmed the high bone turnover rate (Thompson et al., 1969; Eyring and Eisenberg, 1968). Although usually a generalized disease, involvement of a single bone may occur (Thompson et al., 1969).

The clinical features and results of laboratory studies in a further case of this rare disorder are outlined in this report. In addition, the acute response to treatment with synthetic human calcitonin is described. It is expected that the raised bone turnover will eventually fall to normal as occurs in adult Paget's disease (Woodhouse et al., 1971). The preliminary results were very encouraging.

\section{Case Report}

The patient was born on 7 October 1966, the only son of nonconsanguinous Scottish parents and the product of a full-term normal delivery. At the time of study he was aged 5 years (Fig. 1).

Departments of Medicine and Chemical Pathology, Royal Postgraduate Medical School, Hammersmith Hospital, London W.12 N. J. Y. WOODHOUSE, M.R.C.P., Research Fellow and Honorary Senior Registrar

M. T. FISHER, A.N.Z.I.M.L.T., Senior Technologist

G. SIGURDSSON, cAND. MRD., Research Fellow

G. F. JOPLIN, PH.D., F.R.C.P., Consultant Physician

I. MAcINTYRE, M.B., F.R.G.PATH., Professor of Endocrine Chemistry

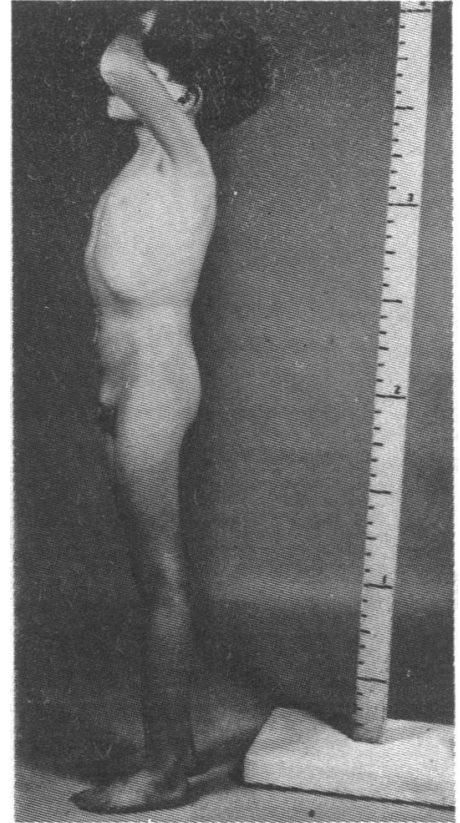

FIG. 1-The patient at the age of 5 . Note the anterior bowing of both legs.

Date and Site of Fractures in Patient with Fuvenile Paget's Disease (Date of Birth 7 October 1966)

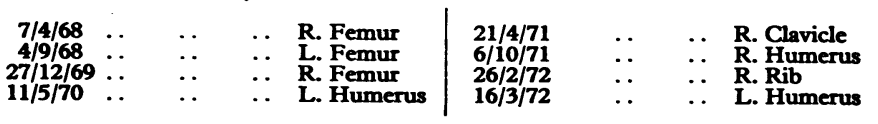

There was no family history of bone disease, and biochemical screening of the parents was normal.

The illness was first noted at the age of $1 \frac{1}{2}$ years, after a fall and fracture of the right femur. Since then seven further fractures have occurred, all in the long bones (see Table). All fractures healed normally. There has been no chronic bone pain. The alkaline phosphatase levels had always been very high, and were still rising (Fig. 2), and the bone deformities were progressive. The home diet was normal, containing about 620 IU of vitamin $\mathrm{D}$, and 1,200 $\mathrm{mg}$ of calcium a day.

At examination the height was $119 \mathrm{~cm}$ (97th percentile), and the weight was $20 \mathrm{~kg}$ (75th percentile). Bone deformity was apparent in the left humerus and both tibiae. There was asymmetrical deformity of the forehead. There was no bone tenderness or bruit, the overlying skin was not unduly warm, and the sclerae were white. The blood pressure was $120 / 80 \mathrm{~mm}$ Hg. Muscularity was normal. Other systems were clinically normal.

The patient was studied under metabolic balance conditions using chromium sesquioxide as a faecal marker (Whitby and Lang, 1960). Seven days equilibration was followed by a nine-day control balance, and 15 days' balance on synthetic human calcitonin (CibaGeigy 47 175-Ba) (Sieber et al., 1970) $0.5 \mathrm{mg}$ intramuscularly twice daily. He was then discharged home on the same treatment.

Standard Autoanalyser techniques were used for the serum biochemistry and urine uric acid, phosphate, and faecal phosphate (Wootton, 1964). Urine and faecal calciums were measured by flame spectrophotometry (MacIntyre, 1960), urine hydroxyproline by the method of Kivirikko et al. (1967), and faecal chromium by modification (Fisher et al., 1972) of the method of Hartford (1953).

Investigations were: haemoglobin $13 \cdot 1 \mathrm{~g} / 100 \mathrm{ml}$, W.B.C. 5,900/ $\mathrm{mm}^{3}$, E.S.R. $4 \mathrm{~mm}$ in one hour, blood urea $24 \mathrm{mg} / 100 \mathrm{ml}$, serum uric acid $4.8 \mathrm{mg} / 100 \mathrm{ml}$, albumin $4.2 \mathrm{~g} / 100 \mathrm{ml}$, 5-nucleotidase $1 \mathrm{IU}$, urine uric acid 0.38 and $0.17 \mathrm{~g} / 24 \mathrm{hr}$ (normal for adults $<0.4$ g). 


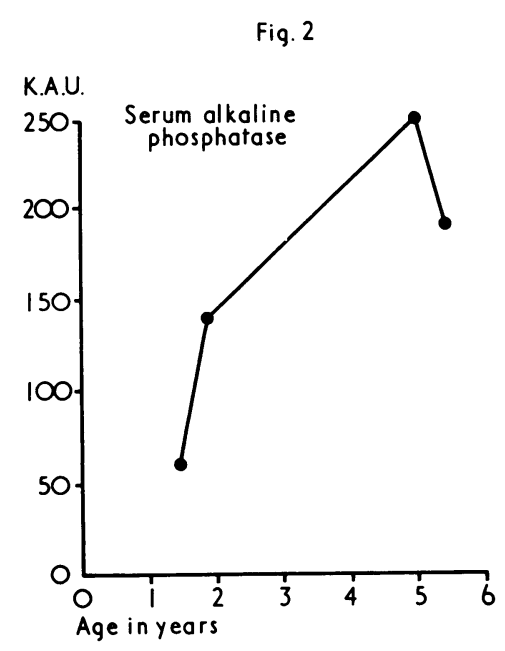

FIG.2-Graph showing serum alkaline phosphatase levels which had been per sistently raised from one year old.

FIG. 3- $X$-ray picture of right femur showing deformity and the abnormal modelling.

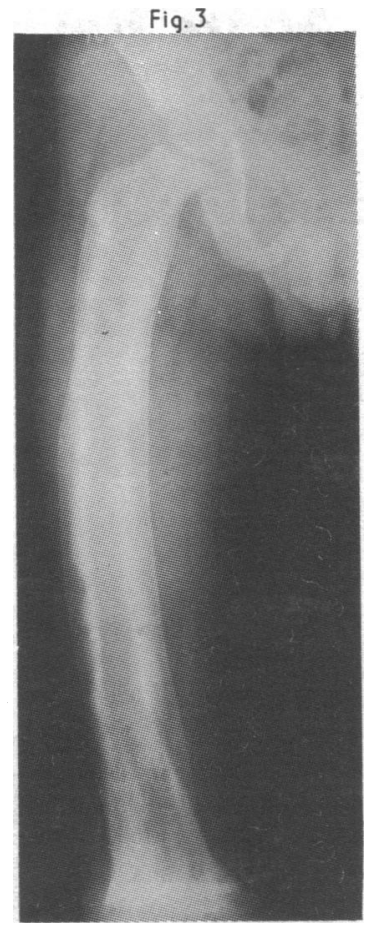

Serum alkaline phosphatase was 192, 192, 176 K.A.U. (normal <25) (Dunnigan and Gardner, 1965), most of which was of bone origin (Dr. D. Moss). The total acid phosphatase was 6.3 and $7 \cdot 2$ K.A.U. (normal adult range $1 \cdot 5-3 \cdot 5$ ).

$X$-ray pictures (Dr. F. H. Doyle) showed widespread abnormalities in bone structure, the most striking being in the diaphyses of the long bones of the limbs (Fig. 3). Their girth was increased with loss of the normal tubulation. Evidence of increased subperiosteal apposition of bone was seen. The cortex, although generally thicker than that seen in a normal long bone, varied greatly in density and thickness, and in parts had a poorly-defined endosteal margin.

The ribs, clavicles, and pelvis were less abnormal. The skull vault was thickened, with loss of diploic space. In relation to height, the vertebral bodies were long and wide, and the disc spaces wide. The bones of the hands were abnormal, the phalangeal cortices showing longitudinal striation. The appearances of some bones resembled polyostotic fibrous displasia, and others adult Paget's disease.

A transiliac trephine bone biopsy (Dr. P. Bordier) showed a grossly abnormal appearance. No differentiation into cortex and cancellous zones could be seen, owing to almost complete replacement by woven bone. No haversian systems and very little lamellar bone were found. A striking mosaic appearance was seen. There was a noticeable increase in the proportion of bone surface showing active bone resorption. Osteoclasts were numerous, and there was appreciable enlargement of the osteocytic lacunae in the woven bone. Osteoblastic bone formation was also greatly increased, and $75 \%$ of the bone surface was covered with osteoid which had a normal calcification front. The appearances were similar to those of very severe Paget's disease, in particular the mosaic pattern.

Effect of calcitonin. - The serum calcium (normal 4.5-5.5 mEq/1.) fell from pretreatment values of $5 \cdot 6,5 \cdot 4$, and $5 \cdot 1$ to $4 \cdot 8,4 \cdot 8,4 \cdot 2$ $\mathrm{mEq} / \mathrm{l}$, individual values being taken fasting on different days. The serum phosphate (normal for age $2 \cdot 0-3 \cdot 2 \mathrm{mEq} / 1$.) (Thalassinos et al., 1970) also fell slightly from $2.9,3.4$, and 3.7 to $2.4,2.9$, and $2.4 \mathrm{mEq} / 1$. The urine hydroxyproline (normal for age $<60 \mathrm{mg} /$ $24 \mathrm{hr}$ ) (Pappas, et al., 1971) was initially extremely high. It fell immediately (Fig. 4) from a mean of $687 \mathrm{mg} /$ day to a new plateau of $408 \mathrm{mg} /$ day. The chromium-corrected calcium and phosphate balances are shown in Fig. 5. The control urine calcium averaged $76 \mathrm{mg} / \mathrm{day}$, and showed no change apart from a fall to $10 \mathrm{mg}$ on the first day of treatment. The faecal calcium fell $(P<0.01)$ from a mean of $912 \mathrm{mg} /$ day in the three control pools to $584 \mathrm{mg} /$ day in the last three pools on calcitonin. (The faecal calcium expressed as "per gramme dry weight" or as "per gramme of nitrogen" gave falls reaching the same levels of significance.) Thus the calcium balance became more positive on calcitonin, rising from +354 $\mathrm{mg} /$ day to $+658 \mathrm{mg} /$ day. The urine phosphate showed no change,

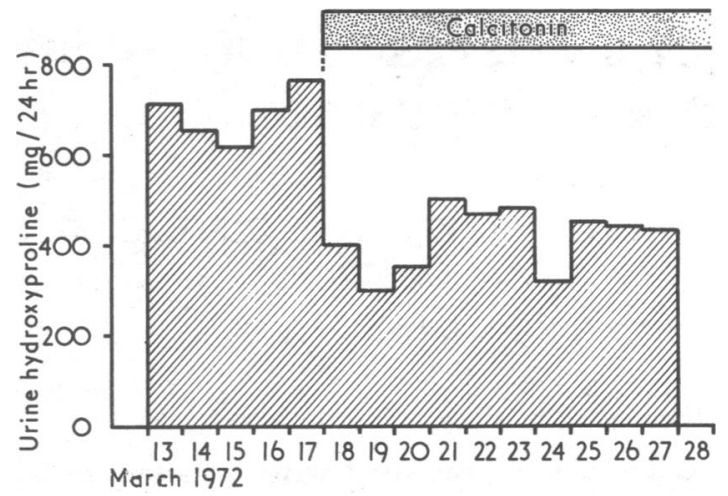

FIG. 4-Acute effect of synthetic human calcitonin on urine hydroxyproline.

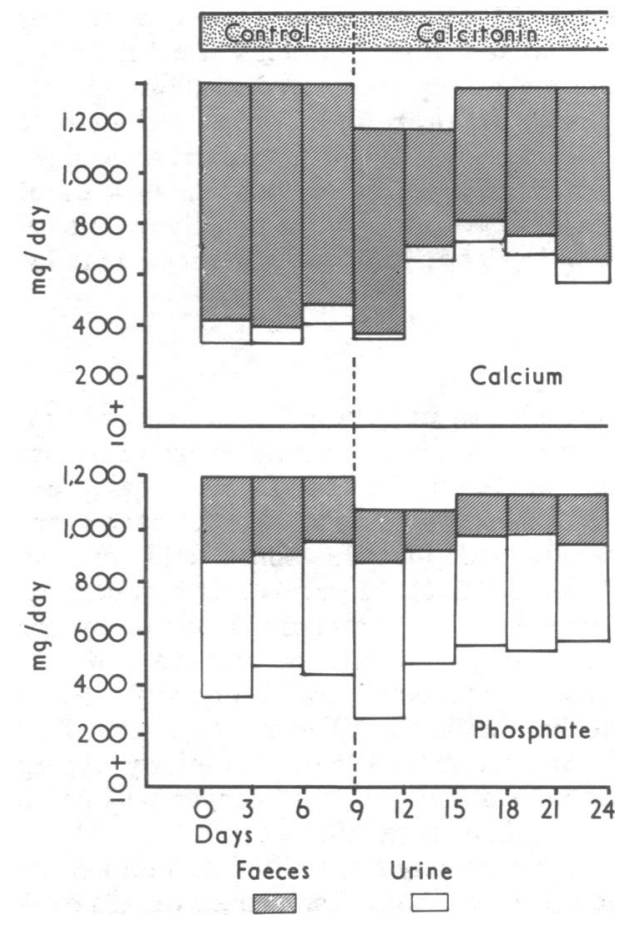

FIG. 5-Calcium and phosphate balance (chromium corrected) before and during calcitonin therapy. Both calcium and phosphate balance became more positive during treatment.

apart from a small rise during the first pool on calcitonin from a mean control output of $484 \mathrm{mg} /$ day to $595 \mathrm{mg} /$ day. Faecal phosphate fell from the control output of $289 \mathrm{mg} /$ day to $167 \mathrm{mg} /$ day in the last three pools on treatment $(P<0.05)$. Thus phosphate balance became more positive, rising from $+394 \mathrm{mg} /$ day to $+555 \mathrm{mg} /$ day. Nitrogen balance showed no change. Faecal fat averaged $2.5 \mathrm{~g} /$ day.

\section{Discussion}

Human calcitonin has produced a pronounced reduction in bone turnover in a patient with juvenile Paget's disease, evidenced by an immediate and sustained fall in urine hydroxyproline excretion. At the same time intestinal calcium absorption increased. This was probably due to a rise in circulating parathyroid hormone (Woodhouse et al., 1971) or 1,25 dihydroxycholecalciferol (Galante et al., 1972) levels, or both. These changes also occur in adult patients with Paget's disease, in whom bone turnover returns to normal during long-term treatment with human synthetic calcitonin (Woodhouse et al., 1971). A similar response in the present patient may be expected. The aim of such treatment is to prevent further bone deformity and to reduce the excessive bone fragility. As normal lamellar bone is formed 
during human calcitonin administration (Woodhouse et al., 1971 ; Bordier et al., 1972) the latter is possible and could lead to a reduction in deformity. Whether or not the bone fragility can be reduced depends on its cause. If as previously suggested the disease process is a variant of fragilitas ossium (Eyring and Eisenberg, 1968) then a favourable result is unlikely. If, however, the fragility is due simply to the formation of structurally abnormal bone as in adult Paget's disease (Schmorl, 1932; Bordier et al., 1972) successful treatment should prevent further fractures.

The histological findings in this case were similar to the other children previously reported (Eyring and Eisenberg, 1968; Thompson et al., 1969) and confirm the increased bone turnover; active osteoclasts and active osteoblasts were greatly increased in number. The changes in the present patient were indistinguishable from those found in active adult Paget's disease (Schmorl, 1932). It is interesting to note that a similar patient with severe radiological changes had a normal serum alkaline phosphatase level, although osteoclasts and osteoblasts were abundant in the bone biopsy specimen (Bakwin and Elger, 1956). Loss of bone mass assessed radiologically has sometimes been reported but this was not observed in the present patient. Reduced bone mass would result from a relative increase in bone resorption over bone formation, a situation likely to be made worse or initiated by the gross restriction in physical activity that is frequently seen, and also by the occasional reported use of steroid medication (Eyring and Eisenberg, 1968).

There are many striking similarities between adult Paget's disease and the high turnover bone disease described in children; serum alkaline and serum acid phosphatase levels are raised, urine hydroxyproline excretion is increased, and a mosaic pattern is present in the bone biopsy samples. Because of this, and to simplify matters, we used the eponym "Paget's" disease to describe the present patient, although we are fully aware that there is no proof linking the two diseases processes.

We wish to thank Dr. A. Glen and Mr. A. McDougal, of the Victoria Infirmary, Glasgow, for kindly allowing us to study a patient under their care, Dr. H. Hobitz and Professor M. Staehelin, of Ciba-Geigy Limited, for support and supplies of human calcitonin, and Sister K. Boon and Miss E. Priestly for skilled help with the balance. This work was in part supported by the Welloome Trust and the Medical Research Council (I. MacI.).
Correspondence should be addressed to: Dr. G. F. Joplin, Royal Postgraduate Medical School, Ducane Road, London W12 0HS.

\section{Addendum}

After three months' treatment a further reduction in bone turnover occurred. Serum alkaline phosphatase fell from 187 to 95 K.A.U., and urine hydroxyproline fell from 687 to $327 \mathrm{mg} \mathrm{a}$ day. In spite of several hard falls no further fractures occurred. Occasional mild nausea was the only reported side effect of the injections.

\section{References}

Bakwin, H., Elger, M. S. (1956). Fournal of Pediatrics, 49, 558.

Bordier, Ph., Woodhouse, N. J. Y., Joplin, G. F., and MacIntyre, I. (1972). fournal of Bone and foint Surgery. In press.

Caffey, J. (1961). Pediatric X-ray Diagnosis, 4th edn., p. 1042. Chicago, Year Book Medical Publishers.

Choremis, C., Yannakos, D., Papadatos, C., and Baroutsou, E. (1958). Helvetica Paediatrica Acta, 13, 185.

Dunnigan, M. G., and Gardner, M. D. (1965). Scottish Medical fournal, 10,325 . Eyring, E. J., and Eisenberg, E. (1968). Fournal of Bone and foint Surgery,

Facon, I. G., Moreira, G., Uehlinger, E., and Giedion, A. (1964). Helviteca Paediatrica Acta, 19, 279.

Fisher, M. T., Atkins, P. A., and Joplin, G. F. (1972). Clinica Chimica Acta,

In press.
Galante, L., Colston, K. W., Macauley, S. J., and MacIntyre, I. (1972).

Nature, In press.
Hartford, W. H. (1953). Analytical Biochemistry, 25, 290.

Kivirikko, K. I., Laitinen, O., and Prockop, D. J. (1967). Analytical Biochemistry, $19,249$.

MacIntyre, $\mathbf{1}$. (1960). Advances in Clinical Chemistry, 4, 1.

Marshall, W. C., and Moncrieff, A. A. (1962). Proceedings of the Royal Society of Medicine, 55, 238.

Pappas, A. M., Miller, M. E., Anderson, M., and Green, W. T. (1971). Clinical Orthopaedics and Related Research, 74, 241.

Schmorl, G. (1932). Virchows Archiv für pathologische Anatomie und Physiologie und für klinische Medizin, 283, 694.

Sieber, P., Riniker, B., Brugger, M., Kamber, B., and Rittel, W. (1970). Helvetica Chimica Acta, 53, 2135.

Stimmerman, G. N. (1966). American fournal of Pathology, 48, 641.

Swoboda, J. W. (1958). Helvetica Paediatrica Acta, 13, 292.

Thalassinos, N. C., Leese, B., Latham, S. C., and Joplin, G. F. (1970). Archives of Disease in Childhood 45, S. C.

Thompson, R. C., Gaull, G. E., Horwitz, S. J., and Schenk, R. K. (1969). American fournal of Medicine, 47, 209.

Whitby, L. G., and Lang, D. (1960). Fournal of Clinical Investigation, 39, 854. Woodhouse, N. J. Y., et al. (1971). Lancet, 2, 1139.

Wootton, I. D. P. (editor) (1964). Microanalysis in Medical Biochemistry, New York, Grune and Stratton.

\title{
Pulmonary Aspiration after Fibre-endoscopy of the Upper Gastrointestinal Tract
}

\author{
B. J. PROUT, C. METREWELI
}

British Medical fournal, 1972, 4, 269-271

\section{Summary}

Pulmonary aspiration occurred in 16 out of 65 patients (24.6\%) undergoing fibre-endoscopic examinations of the upper gastrointestinal tract under intravenous sedation, but it was rarely followed by serious complications. Aspiration was found to occur under sedation with diazepam alone, diazepam with atropine, and with chlormethiazole. The most important factors contributing to aspiration are the local pharyngeal

Royal Cornwall Hospital, Truro, Cornwall

B. J. PROUT, M.D., M.R.C.P., Consultant Physician

C. METREWELI, M.B., B.CHIR., Registrar anaesthesia and the mechanical interference of the fibrescope with laryngeal closure and swallowing. The patient is also at risk of aspiration after completion of the procedure and should remain recumbent until the local anaesthesia has worn off.

\section{Introduction}

Fibre-endoscopic examination of the gastrointestinal tract under intravenous sedation is now widely practised. We have been concerned with the possible danger of aspiration into the lungs during this procedure, and we have looked at the potential factors involved in increasing the risk. These are the nature of the sedative agent, the dose of the agent used, local oropharyngeal anaesthesia, and the use of antisialogogues. 